\title{
Olfactory Identification Test Using Familiar Distracters for Koreans
}

\author{
Jae-Myung Kim ${ }^{1} \cdot$ Mi Soon Jeong ${ }^{2} \cdot$ Dong-Hyuk Shin ${ }^{1} \cdot$ Jeong-Hun Seol ${ }^{1} \cdot$ Seok-Chan Hong ${ }^{1}$ \\ Jae Hoon $\mathrm{Cho}^{1} \cdot$ Jin Kook Kim ${ }^{1}$ \\ ${ }^{1}$ Department of Otorhinolaryngology-Head \& Neck Surgery, Konkuk University School of Medicine, Seoul; \\ ${ }^{2}$ Galimard Perfume \& Flavor School, Seoul, Korea
}

Clinical and Experimental Otorhinolaryngology 2014;7:19-23

http://dx.doi.org/10.3342/ceo.2014.7.1.19

\section{Erratum: Correction of Figure}

We found an error in this article. The legend of figure was incorrectly presented in Fig. 1. The correct figure is as follows.

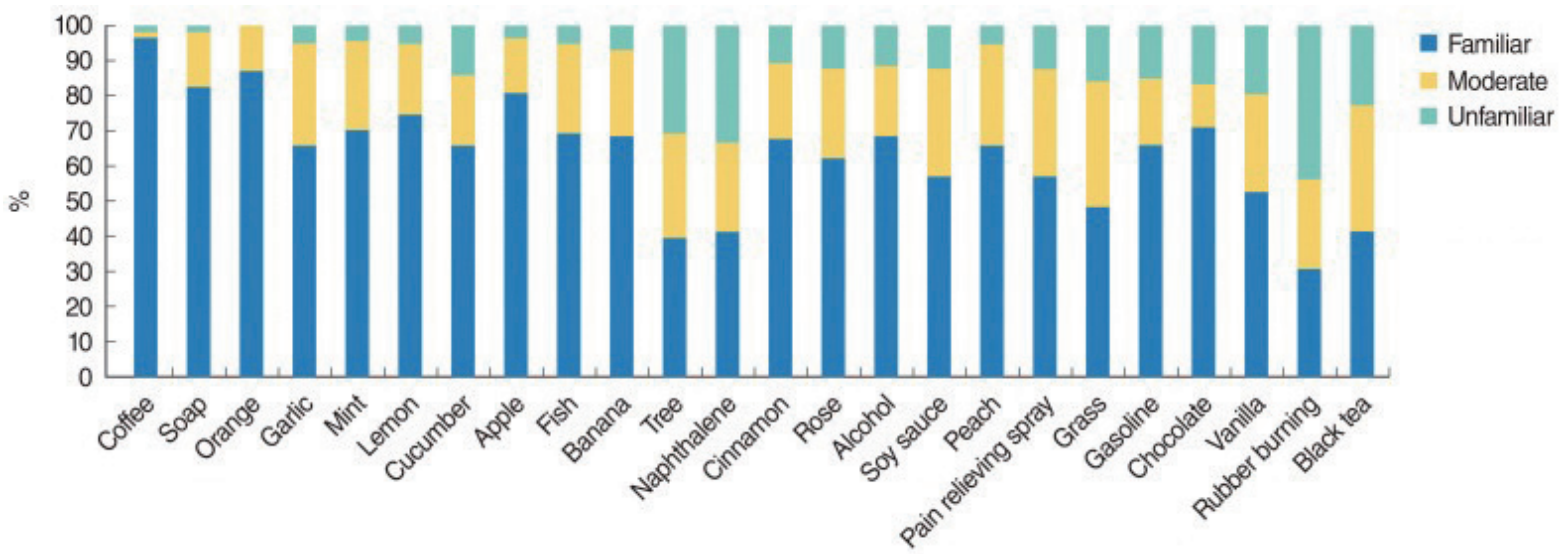

Copyright (C) 2020 by Korean Society of Otorhinolaryngology-Head and Neck Surgery.

This is an open-access article distributed under the terms of the Creative Commons Attribution Non-Commercial License (https://creativecommons.org/licenses/by-nc/4.0)

which permits unrestricted non-commercial use, distribution, and reproduction in any medium, provided the original work is properly cited. 